\title{
Electrodeposition of Super-Hydrophobic Nickel Film on Magnesium Alloy AZ31 and Its Corrosion Resistance
}

\author{
Baojun Han ${ }^{1,2, *}$, Yang Yang ${ }^{2}$, Ling Fang ${ }^{1,2}$, Guanghuai Peng ${ }^{1,2}$, Chubin Yang ${ }^{1,2}$ \\ ${ }^{1}$ Jiangxi Provincial Engineering Research Center for Magnesium alloys, GanNan Normal University, \\ Ganzhou 341000, PR China \\ ${ }^{2}$ School of Chemistry and Chemical Engineering, GanNan Normal University, Ganzhou 341000, PR \\ China \\ *E-mail: bao77junhan@yahoo.com
}

doi: $10.20964 / 2016.11 .23$

Received: 30 July 2016 / Accepted: 9 September 2016 / Published: 10 October 2016

\begin{abstract}
Super-hydrophobic surface has been widely studied owing to its various distinct functions. The original microstructures of the characteristic plant leaves, which are super-hydrophobic, have inspired researchers to design and manufacture synthetic super-hydrophobic surface. Among all the structuralmetal materials, magnesium alloy, which is the lightest alloy, was restricted because of its low resistance to erosion. Through the nickel electrodeposition approach, a super-hydrophobic surface, which possess self-cleaning feature, was succeeded to be deposited on AZ31 Mg alloy. To study the wettability of the nickel film, which is super-hydrophobic, the surface was exposed under air ambient at room temperature, where the water contact angle is $151.7^{\circ}$. Moreover, electrochemical impedance spectroscopy (EIS) and Tafel polarization measurements were employed to evaluate the erosion resistance of the super-hydrophobic surface.
\end{abstract}

Keywords: Electrodeposition, Nickel, Magnesium alloy; EIS, Corrosion; Potentiodynamic polarization

\section{$\underline{\text { FULL TEXT }}$}

(C) 2016 The Authors. Published by ESG (www.electrochemsci.org). This article is an open access article distributed under the terms and conditions of the Creative Commons Attribution license (http://creativecommons.org/licenses/by/4.0/). 